\title{
The divergent ventilatory and heart rate response to moderate hypercapnia in infants with apnoea of infancy
}

Miriam Katz-Salamon, Joseph Milerad

\begin{abstract}
Background-Inspired $\mathrm{CO}_{2}$ is a potent ventilatory stimulant exhibiting a paradoxical inhibitory effect on breathing at high concentrations. Severe respiratory depression as a result of $\mathrm{CO}_{2}$ rebreathing during sleep has been implicated as a possible trigger factor in sudden infant death syndrome (SIDS).

Objective-To investigate the ventilatory and heart rate (HR) responses to inhaled $\mathrm{CO}_{2}$ in infants with apnoea of infancy, a group believed to be at increased risk of SIDS.
\end{abstract}

Study design-Thirty one infants with severe sleep related apnoea, 31 infants with mild recurrent apnoea, and 31 age and sex matched controls for the infants with severe sleep related apnoea were studied. HR was computed from digitised RR intervals, "ventilation" was recorded by inductance plethysmography, and $\mathrm{PCO}_{2}$ and $\mathrm{Po}_{2}$ were monitored by transcutaneous electrodes. The ventilatory and $H R$ responses to $\mathrm{CO}_{2}$ were expressed as percentage increase in ventilation and change in HR/unit change in transcutaneous $\mathrm{PCO}_{2}$.

Results-The mean increase in transcutaneous $\mathrm{PCO}_{2}$ during $\mathrm{CO}_{2}$ challenge $(0.45$ $\mathrm{kPa}=3.4 \mathrm{~mm} \mathrm{Hg}$ ) resulted in a mean increase in ventilation of $291 \% / 1 \mathrm{kPa}$ $(7.3 \mathrm{~mm} \mathrm{Hg})$ increase in transcutaneous $\mathrm{PCO}_{2}$, with no difference between the groups. A significant difference between infants with severe sleep related apnoea and mild recurrent apnoea versus controls $(\mathrm{p}<0.02, \mathrm{p}<0.01$, respectively) was found in their $\mathrm{HR}$ response to $\mathrm{CO}_{2}$ challenge: HR decreased in 12 severe sleep related apnoea infants and 10 infants with mild recurrent apnoea, but only in two controls.

Conclusion-Infants with apnoea of infancy frequently show a paradoxical decrease in $\mathrm{HR}$ during $\mathrm{CO}_{2}$ challenge, possibly because of an insufficient ability

Neonatal Unit, Department of Woman and Child Health, Karolinska Hospital, S-171 76 Stockholm, Sweden

M Katz-Salamon

J Milerad

Correspondence to: Dr Katz-Salamon.

Accepted 14 April 1998
During physiological rest, such as quiet sleep, the homeostatic regulation of "ventilation" is
Keywords: hypercapnia; sudden infant death syndrome; apnoea; heart rate governed by feedback mechanisms based on information from peripheral and intracranial chemoreceptors. ${ }^{1}$ A prerequisite for rhythmic and efficient respiration is the adequate functioning of afferent inputs from the chemoreceptive structures that sense $\mathrm{pH}$ values and $\mathrm{CO}_{2}$ and $\mathrm{O}_{2}$ concentrations in plasma and cerebrospinal fluid.

Inspired fractional $\mathrm{CO}_{2}$ concentrations in the range of $1-8 \%$ have potent stimulatory effects on ventilation. Thus, the ventilatory response to inhalation of $\mathrm{CO}_{2}$ enriched gas has long been used as a standard test of the function of the central chemoreceptor structures. However, excessive concentrations of $\mathrm{CO}_{2}(>8 \%)$ do produce a paradoxical inhibition of respiration. ${ }^{2}$

Thus, $\mathrm{CO}_{2}$ has dual effects on respiratory control, it is a potent ventilatory stimulant in moderate concentrations and acts as a ventilatory inhibitor at high concentrations. The depressive effects of $\mathrm{CO}_{2}$ rebreathing might elicit central ventilatory depression, leading to hypercarbia and hypoxaemia. This scenario has been proposed as a mechanism for the increased risk of sudden infant death syndrome (SIDS) when sleeping in the prone position. ${ }^{34}$

One might speculate that a deterioration in the ability to increase ventilation in response to $\mathrm{CO}_{2}$ might be parallelled with a propensity to $\mathrm{CO}_{2}$ induced depression of respiration. This has been shown in preterm babies who have an attenuated ventilatory response to $\mathrm{CO}_{2}{ }^{5}$ and a lower threshold for inhibition of ventilation when subjected to hypercapnia. ${ }^{6}$ However, an association between $\mathrm{CO}_{2}$ response and increased sensitivity to $\mathrm{CO}_{2}$ induced depression has not been shown in term infants who have experienced severe apnoea as a result of an apparent life threatening event.

Thus, an attenuation of other physiological responses might be a more sensitive indicator of increased vulnerability to the depressive effects of $\mathrm{CO}_{2}$.

An increase in heart rate (HR) is nearly always part of the physiological response to exogenous stress, and infants who are likely to experience hypercapnic episodes - infants with apnoea of infancy - in spite of a normal ventilatory response to $\mathrm{CO}_{2}$, might have a reduced ability to activate cardiac responses when subjected to $\mathrm{CO}_{2}$ accumulation.

We tested this hypothesis by comparing the ventilatory and HR responses to mild hypercapnia ( $4 \%$ in room air) in infants who had suffered severe sleep related apnoea with age and sex matched controls. In addition, these 
Table 1 Background data of infants with severe sleep related apnoea (SSRA), mild recurrent apnoea $(M R A)$, and controls

\begin{tabular}{lllll}
\hline & SSRA & MRA & Controls & p value \\
\hline Birth weight (g) & $3565(118)$ & $3107(192)$ & $3478(131)$ & 0.06 \\
Gestational age at birth (weeks) & $39(0.4)$ & $38(0.8)$ & $39(0.3)$ & $0.03^{\star}$ \\
Study weight (g) & $6160(308)$ & $5529(364)$ & $5837(370)$ & 0.51 \\
Study age (months) & $3.7(0.5)$ & $2.8(0.2)$ & $3.5(0.3)$ & 0.19 \\
\hline
\end{tabular}

Values are mean (SD).

$\star \mathrm{MRI} \neq$ controls and SSRA.

two groups were compared with infants who had experienced recurrent apnoeic episodes that did not necessarily occur during sleep and had not required resuscitation.

\section{Methods}

SUBJECTS

The study population consisted of infants with apnoea of infancy who were subdivided into two groups based on clinical features: 31 infants with severe sleep related apnoea, and 31 infants with mild recurrent apnoea. The third group consisted of age and sex matched controls for infants with severe sleep related apnoea.

Infants with severe sleep related apnoea

Severe sleep related apnoea was defined as a sleep related episode where the infant was found apparently lifeless, limp, pale, or cyanotic, and where vigorous stimulation or cardiopulmonary resuscitation was required. One infant had a previous sibling who died of SIDS. The diagnosis was based on case history as given by the parents and, in some cases, confirmed by other witnesses and/or the ambulance personnel. This group fulfilled the criteria of apparent life threatening events.

Infants with mild recurrent apnoea

Mild recurrent apnoea was defined as two or more episodes of apnoea associated with pallor
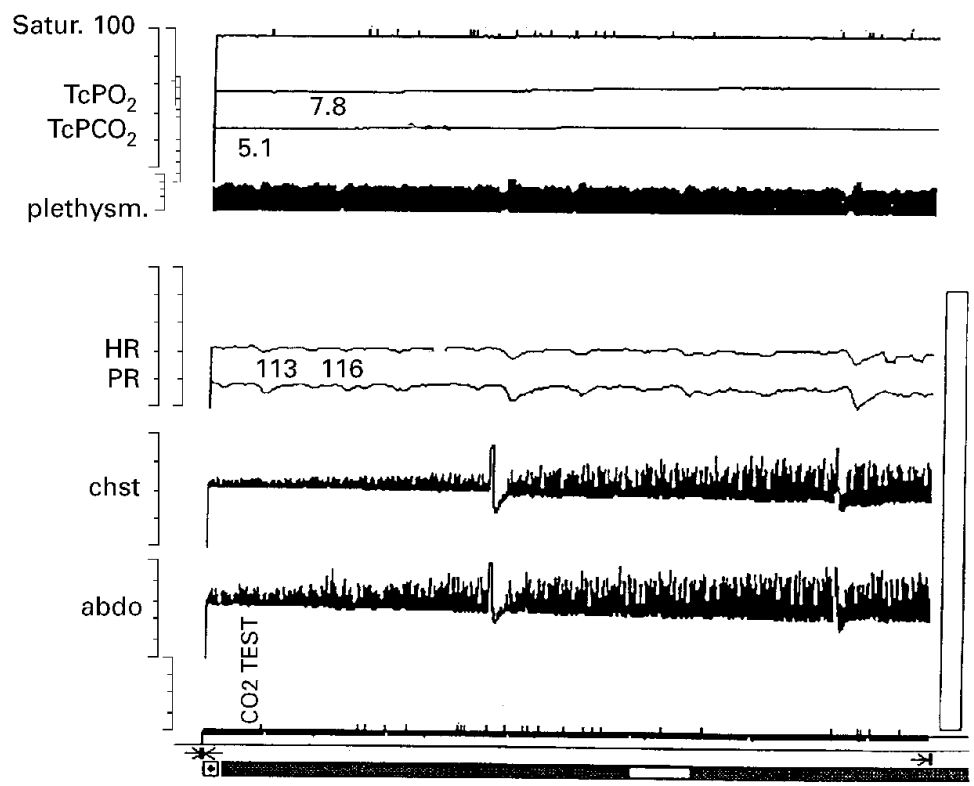

Figure 1 Tracing of the polysomnographic recording including saturation (Satur.), transcutaneous (Tc) $\mathrm{PO}_{2}$ and $\mathrm{PCO}_{2}$, heart rate (HR, beats/min), pulse rate (PR), and respiratory movements of chest (chst) and abdomen (abdo). or colour change. Resuscitation or vigorous stimulation was not a requirement for diagnosis and the episode might have occurred either during rest or sleep. Thus, the clinical severity of the episodes of mild recurrent apnoea was substantially milder than in severe sleep related apnoea.

\section{Controls}

One age and sex matched control was recruited for each infant with severe sleep related apnoea. When an infant with severe sleep related apnoea was referred for investigation, a letter explaining the purpose of the study was sent to one randomly selected infant born in our nursery who was of the same sex and at the same age as the corresponding patient with severe sleep related apnoea. When written parental consent was obtained, the control infants were admitted for investigation within one to two weeks. These infants were born at term after an uneventful pregnancy and delivery. None of them had a family history of SIDS or apnoea.

Additional background data for the study group are presented in table 1 .

EXPERIMENTAL MONITORING PROCEDURES

Infants in both apnoea groups (severe sleep related apnoea and mild recurrent apnoea) were referred to us for investigation after a three day hospitalisation, during which other possible causes of apnoea such as infection, congenital heart disease, or seizure disorder had been ruled out.

All infants were admitted to the laboratory at around 20:00 and put to sleep supine and lightly dressed. The room temperature was kept at $23-25^{\circ} \mathrm{C}$ and lights were dimmed. A computerised polysomnography unit (CARDAS, Maternal and Infant Telemonitoring Centre, Oxford, UK) that allowed digital storage of eight analogue channels, real time replay of the stored data, and data exchange with commercial statistical packages was used. The CARDAS utilises inductance plethysmography (respitrace) with thoracic and abdominal respibands for non-invasive measurements of tidal volumes and calculation of a sum value that is proportional to tidal volume. A three lead electrocardiogram (ECG) was used for measurements of beat to beat RR intervals and a finger pulse oxymeter probe for measurements of pulse amplitude and $\mathrm{SaO}_{2}$. In addition, skin surface $\mathrm{PO}_{2}$ (transcutaneous $\mathrm{PO}_{2}$ ) and $\mathrm{PCO}_{2}$ (transcutaneous $\mathrm{PCO}_{2}$ ) tensions were monitored with a combined transcutaneous electrode (Radiometer TCM3, Copenhagen, Denmark). A calf movement sensor was used for monitoring body position and movements. All the analogue signals of thoracic and abdominal excursions and their sum, oxygen saturation, transcutaneous $\mathrm{PO}_{2}$ and $\mathrm{PCO}_{2}$, and $\mathrm{RR}$ intervals were sampled at 10,20 , and $100 \mathrm{~Hz}$, respectively, converted in a built in 12 bit $\mathrm{AD}$ converter, and stored on the disk of a 486, IBM compatible personal computer. Sleep states (active or quiet sleep) were scored by behavioural criteria ${ }^{8}$ by a single trained observer and compared with a classification of 
Table 2 Saturation, transcutaneous $\mathrm{PO}_{2}$ and $\mathrm{PCO}_{2}$, and heart rate during reference conditions preceding inhalation of $\mathrm{CO}_{2}$ enriched gas mixture

\begin{tabular}{lllll}
\hline & SSRA & MRA & Controls & p value \\
\hline Saturation $\mathrm{O}_{2}(\%)$ & $97(2)$ & $96(3)$ & $96(2)$ & 0.23 \\
Transcutaneous $\mathrm{Po}_{2}(\mathrm{kPa})$ & $10(2)$ & $11(2)$ & $11(1)$ & 0.66 \\
Transcutaneous $\mathrm{PCO}_{2}(\mathrm{kPa})$ & $5.3(0.4)$ & $5.5(0.5)$ & $5.4(0.3)$ & 0.38 \\
Heart rate (beats/min) & $115(14)$ & $113(19)$ & $118(16)$ & 0.43 \\
$\mathrm{SD}_{\text {HR }}$ (beats/min) & $8.6(11.4)$ & $5.2(2.5)$ & $6.1(3.8)$ & 0.15
\end{tabular}

Values are mean (SD).

$\mathrm{SD}_{\mathrm{HR}}$, standard deviation of heart rate; SSRA, infants with severe sleep related apnoea; MRA, infants with mild recurrent apnoea.

Table 3 "Ventilatory" and heart rate responses to changes in transcutaneous (Tc) $\mathrm{PCO}_{2}$

\begin{tabular}{lllll}
\hline & SSRA & MRA & Controls & p value \\
\hline Ventilatory increase $/ 1 \mathrm{kPa} \mathrm{TcPCO}_{2}$ & $247(135)$ & $268(163)$ & $307(167)$ & 0.33 \\
$\Delta \mathrm{HR}$ change $1 \mathrm{kPa} \mathrm{TcPCO}$ & $1.0(8.7)$ & $-1.4(13.4)$ & $5.7(11.8)$ & 0.02
\end{tabular}

Values are mean $(\mathrm{SD})$

SSRA, infants with severe sleep related apnoea; MRA, infants with mild recurrent apnoea.

infant sleep state based on $\mathrm{HR}$ variability scoring. ${ }^{9}$ All infants were monitored during a six to eight hour nocturnal period using the polygraphic procedure as above. During the first quiet sleep period, as defined by behavioural criteria, a $\mathrm{CO}_{2}$ challenge test was performed. A 10 litre polycarbonate head box was placed gently over the head. After a three minute control period in room air using a gas flow through the box of $10 \mathrm{l} / \mathrm{min}$, the gas flow was switched to a $10 \mathrm{l} / \mathrm{min}$ flow of $4 \% \mathrm{CO}_{2}$ in room air. The $\mathrm{CO}_{2}$ inhalation was continued for nine minutes or until the infant moved or changed body position, in which case tidal volumes could no longer be estimated from the excursions of the respibands. The minimum duration of tests accepted for analysis was six minutes. If an infant aroused, had a startle, or changed body position before six minutes had elapsed, the $\mathrm{CO}_{2}$ test was repeated during the following sequence of quiet sleep. As a consequence, a total of five tests had to be repeated.

DATA ANALYSIS

Reference values

The mean $\mathrm{HR}$, transcutaneous $\mathrm{PCO}_{2}$, transcutaneous $\mathrm{PO}_{2}$, and $\mathrm{SaO}_{2}$ during one minute of air breathing preceding the $\mathrm{CO}_{2}$ challenge were used as resting reference values. Because the induction plethysmography device was not calibrated for volume, both tidal volume and minute ventilation are written in quotes.

Changes in "ventilation" were calculated from the respiratory rate multiplied by sum signal of chest and abdominal excursion. The latter corresponded to changes in "tidal volumes".

The mean value of breath by breath "ventilation" ("tidal volume" $\times$ respiratory rate) during one minute immediately preceding the $\mathrm{CO}_{2}$ challenge was used as the reference period "ventilation".

Ventilatory response to $\mathrm{CO}_{2}$

A representative original tracing of the $\mathrm{CO}_{2}$ test is shown in fig 1 . The entire six to nine minute challenge period, from the beginning of $\mathrm{CO}_{2}$ inhalation until the termination of the test, was used to calculate the ventilatory response to $\mathrm{CO}_{2}$. The changes in "ventilation" during $\mathrm{CO}_{2}$
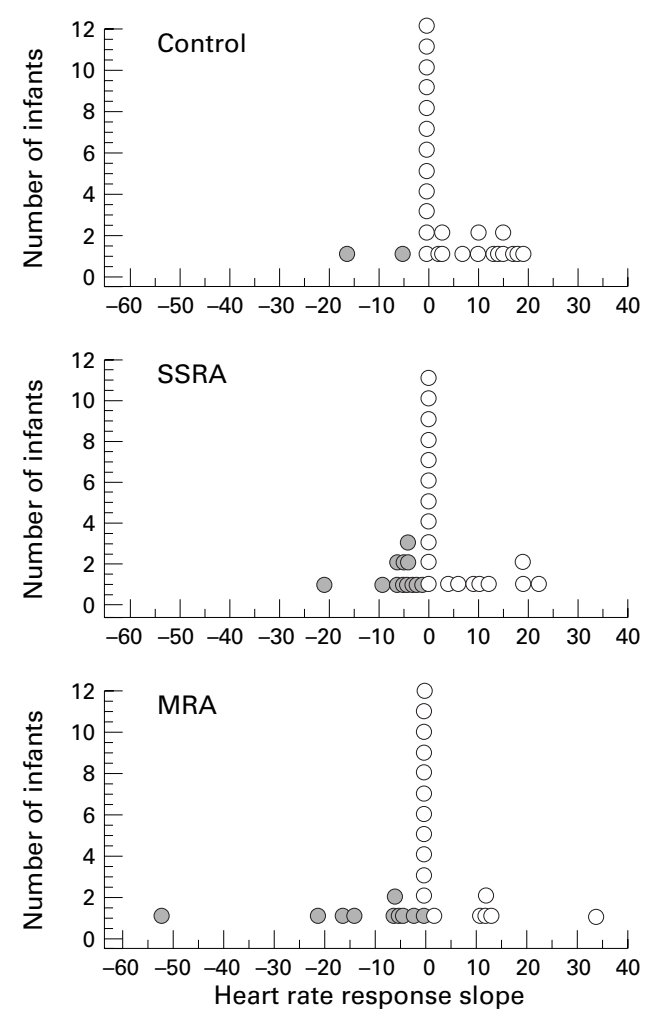

Figure 2 Scatter diagram of the slopes of heart rate response to $\mathrm{CO}_{2}$ inhalation in three infant groups. Each symbol represents the slope of an individual infant. Shaded symbols depict negative slopes. SSRA, severe sleep related apnoea; $M R S$, mild recurrent apnoea.

breathing were expressed as percentage change from the reference period (assigned 100\%). For example, a doubling of "ventilation" was expressed as $200 \%$. Each change from resting "ventilation" was plotted against the corresponding change in transcutaneous $\mathrm{PCO}_{2}$ in a coordinate system, with changes in "ventilation" on the $\mathrm{Y}$ axis and changes in transcutaneous $\mathrm{PCO}_{2}$ on the $\mathrm{X}$ axis. Regression analysis was then used to calculate the above relation. The slope of the regression line describing a percentage change in "ventilation"/unit change in transcutaneous $\mathrm{PCO}_{2}(\Delta$ vent $/ \Delta$ transcutaneous $\mathrm{P}_{2}$ ) was used as an index of the ventilatory response to $\mathrm{CO}_{2}$. The slope of this regression line (the regression coefficient) was tested for significance. A positive slope indicated a significant rise in "ventilation", a negative slope a significant decrease in "ventilation", and a zero slope a non-significant change in "ventilation" during the test.

Heart rate response to $\mathrm{CO}_{2}$

Similarly to the calculations of ventilatory response, the $\mathrm{HR}$ response to $\mathrm{CO}_{2}$ was expressed by plotting instantaneous $\mathrm{HR}$ on the $\mathrm{Y}$ axis against the corresponding transcutaneous $\mathrm{PCO}_{2}$ values on the $\mathrm{X}$ axis. The slope of the regression line $\left(\Delta \mathrm{HR} / \Delta\right.$ transcutaneous $\left.\mathrm{PCO}_{2}\right)$ describes the $\mathrm{HR}$ response to $\mathrm{CO}_{2}$. As above, the slope of the regression line (the regression coefficient) was tested for significance and $\mathrm{p}<0.05$ was considered to be significant. 
Statistical methods

Numerical data of breath by breath $\mathrm{SaO}_{2}$, transcutaneous $\mathrm{PO}_{2}$ and transcutaneous $\mathrm{PCO}_{2}$, the sum of chest and abdominal excursions and $\mathrm{RR}$ intervals were exported from the polygraphic recording as Lotus WKS files and analysed using a commercial statistical package (Statgraphics 6.0).

The differences between severe sleep related apnoea, mild recurrent apnoea, and the control infant groups were tested by Kruskal-Wallis analysis of variance by ranks and, thereafter, by the Mann-Whitney U test. A level of $p<0.05$ was considered to be significant.

\section{Results}

AIR BREATHING

The mean (SD) HR before $\mathrm{CO}_{2}$ challenge for all infants was 115.2 (16.4) beats/min. No significant differences in $\mathrm{HR}$ and $\mathrm{HR}$ variability, expressed as standard deviation of $\mathrm{HR}$ between the three groups of infants, were found. $\mathrm{SaO}_{2}$, transcutaneous $\mathrm{PO}_{2}$, and transcutaneous $\mathrm{PCO}_{2}$ levels were also comparable (table 2).

$\mathrm{CO}_{2}$ STIMULUS

The inhalation of $4 \% \mathrm{CO}_{2}$ in air resulted in a mean increase in transcutaneous $\mathrm{PCO}_{2}$ by $0.45 \mathrm{kPa} \quad(3.4 \mathrm{~mm} \mathrm{Hg})$, range $0.2-0.8 \mathrm{kPa}$ (1.5-6.0 $\mathrm{mm} \mathrm{Hg}$ ). The individual transcutaneous $\mathrm{PCO}_{2}$ values at the beginning of $\mathrm{CO}_{2}$ inhalation varied greatly among individual infants, but the maximal transcutaneous $\mathrm{PCO}_{2}$ values were similar in all three groups.

VENTILATION DURING $\mathrm{CO}_{2}$ BREATHING

"Ventilation" increased significantly and to a similar extent in all subject groups (infants with severe sleep related apnoea, infants with mild recurrent apnoea, and controls; table 3). On average, "ventilation" increased by $291 \% /$ $1 \mathrm{kPa}(7.3 \mathrm{~mm} \mathrm{Hg})$ increase in transcutaneous $\mathrm{PCO}_{2}$.

HEART RATE DURING $\mathrm{CO}_{2}$ BREATHING

In control infants, the slope of $\mathrm{HR}$ changes during $\mathrm{CO}_{2}$ breathing $(\Delta \mathrm{HR} / \Delta$ transcutaneous $\left.\mathrm{PCO}_{2}\right)$ was significantly higher $(\mathrm{p}=0.02)$ than in infants with either severe sleep related apnoea or mild recurrent apnoea $(5.7,1.0$, and -1.4 , respectively). Figure 2 shows that 12 of the infants with severe sleep related apnoea and 10 of the infants with mild recurrent apnoea reacted with a decrease in HR as transcutaneous $\mathrm{PCO}_{2}$ increased, whereas only two of the control infants showed this response pattern. Thus, despite the differences in the clinical severity of an apnoeic episode, the infants with severe sleep related apnoea and mild recurrent apnoea showed a similar HR reaction pattern. The infants in whom the HR decreased in response to $\mathrm{CO}_{2}$ could not be distinguished from the other infants by clinical criteria.

The HR slope was not related to the resting HR ( $p=0.28)$, but was significantly inversely
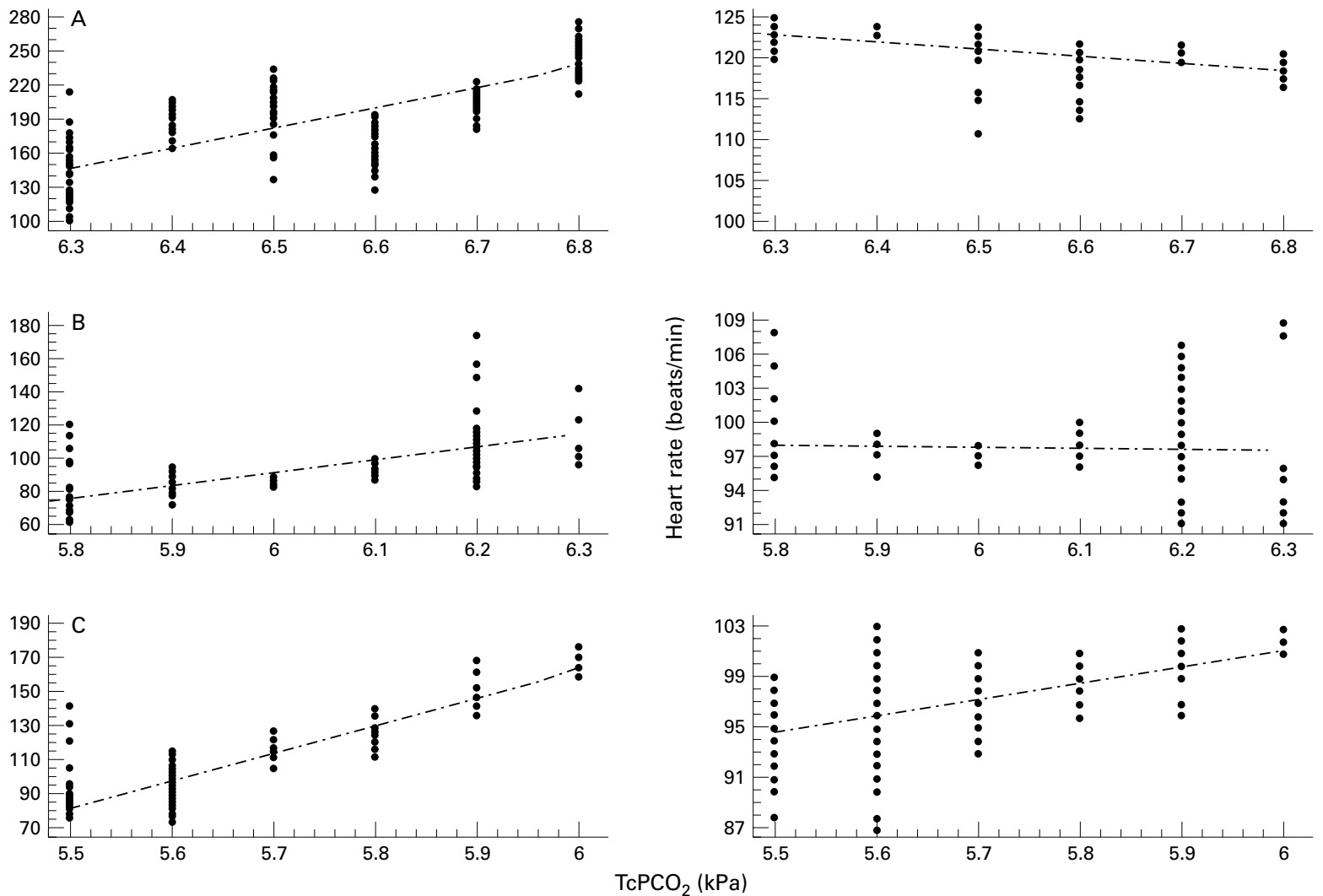

Figure 3 The shape of "ventilatory" and $\mathrm{HR}$ responses to $\mathrm{CO}_{2}$ in three infants illustrating the response modes observed: (A) increase in ventilation and simultaneous decrease in HR; (B) increase in ventilation and no HR response; (C) increase in ventilation with a concomitant increase in HR. Tc, transcutaneous. 
related to the initial transcutaneous $\mathrm{PCO}_{2}$ $(\mathrm{p}=0.002)$, as well as the maximum transcutaneous $\mathrm{PCO}_{2}$ in each individual infant ( $\mathrm{p}=0.005)$.

In all infants studied, the HR response correlated significantly with the ventilatory slope $\quad(p=0.045 ; \quad$ correlation coefficient $r=0.21)$, meaning that the lower the ventilatory response, the lower the probability that the $\mathrm{HR}$ would increase during $\mathrm{CO}_{2}$ challenge. The standard deviation of HR was the same in all infants $(p=0.12)$. Regression analysis showed a strong correlation between standard deviation of $\mathrm{HR}$ in air and in $\mathrm{CO}_{2}(r=0.86$; $\mathrm{p}=0.0001)$. The range of transcutaneous $\mathrm{PCO}_{2}$ had no influence on the standard deviation of HR.

Figure 3 shows the three modes of response to the increased concentration of $\mathrm{CO}_{2}:(1)$ a significant increase in "ventilation" with the concomitant decrease in HR was seen in 24 infants, 12 infants with severe sleep related apnoea, 10 with mild recurrent apnoea, and two controls (fig 3A); (2) a significant increase in "ventilation" with no change in HR was seen in 41 infants, 11 infants with severe sleep related apnoea, 15 infants with mild recurrent apnoea, and 15 controls (fig 3B); and (3) a significant increase in "ventilation" with a concomitant increase in HR was seen in 28 infants, eight infants with severe sleep related apnoea, six infants with mild recurrent apnoea, and 14 controls (fig 3C).

\section{Discussion}

The main finding of this study was that infants with severe sleep related apnoea and infants with mild recurrent apnoea exhibited a divergent $\mathrm{HR}$ response to mild hypercapnia. While most control infants responded with an increase in "ventilation" and an increased or unchanged $\mathrm{HR}$, a decrease in $\mathrm{HR}$ was seen in a significant number of infants with severe sleep related apnoea and infants with mild recurrent apnoea. The lack of increase in $\mathrm{HR}$ during $\mathrm{CO}_{2}$ breathing was associated with higher resting $\mathrm{CO}_{2}$ values and lower ventilatory slopes-less steep and "right-shifted" ventilatory response curves. Thus, changes in $\mathrm{HR}$ during $\mathrm{CO}_{2}$ challenge appear to reflect subtle differences in $\mathrm{CO}_{2}$ sensitivity.

Prone position during sleep together with a slight hypoventilation might result in a $\mathrm{CO}_{2}$ accumulation around the face of as much as $10 \%{ }^{4}$ Although such excessive $\mathrm{CO}_{2}$ provocation was not part of the study protocol, one could speculate on the basis of the present results that a combination of hypoventilation and bradycardia could occur under such circumstances and put the infant at risk of asphyxia.

$\mathrm{CO}_{2}$ is unique as a physiological stimulus in that it acts as a potent ventilatory stimulant at low concentrations but can inhibit breathing at high concentrations. The threshold values for producing ventilatory depression vary among individuals. The inhibitory effects can be seen at lower $\mathrm{CO}_{2}$ concentrations in preterm babies than in term infants. ${ }^{5}$ The mechanisms of $\mathrm{CO}_{2}$ induced inhibition have not been elucidated in detail, but are believed by some authors to be a result of a sensory inhibitory reflex located in the upper airway. ${ }^{10}$ Our results suggest the presence of a central inhibitory mechanism operational at physiological alveolar $\mathrm{CO}_{2}$ concentrations that primarily affects the HR response to exogenous stimuli.

Although some infants with severe sleep related apnoea or mild recurrent apnoea do have blunted ventilatory and arousal responsiveness to $\mathrm{CO}_{2},{ }^{11}{ }^{12}$ there are conflicting opinions about whether apnoeic infants as a group have a normal or attenuated ventilatory sensitivity to inhaled $\mathrm{CO}_{2}{ }^{7}$ This controversy might result in part from the different methodologies used in different studies. ${ }^{13}$ A prime concern in our investigation was to use non-invasive monitoring techniques that would not require sedation or interfere with normal sleep. Induction plethysmography was chosen to monitor changes in ventilation ${ }^{14-16}$ and is widely used.

The ventilatory changes estimated by inductance plethysmography were correlated to changes in transcutaneous $\mathrm{CO}_{2}$ and not end tidal $\mathrm{PCO}_{2}$ to avoid irritation of the nasal orifice by a sampling tube. A similar method has been described previously by Hazinski et al and Schafer et al. ${ }^{18}{ }^{18}$ However, this meant that only relative changes in ventilation (percentage change from control) could be assessed. Another limitation of our method was that a low concentration of $\mathrm{CO}_{2}$ was used and an equilibrium between inhaled, alveolar, and central $\mathrm{CO}_{2}$ values might not have occurred; consequently, the response slopes obtained might not accurately reflect central chemoreceptor activity. These disadvantages were considered and balanced against the need to perform the test during physiological conditions without causing sympathetic activation as a result of tactile or other stimuli. Given the limitations of our technique, the results of the $\mathrm{CO}_{2}$ challenge tests do support previous reports suggesting that the magnitude of the $\mathrm{CO}_{2}$ ventilatory response of apnoeic infants is within the range of controls.

The observed differences between controls and infants with severe sleep related apnoea or mild recurrent apnoea were confined to the HR response to inhaled $\mathrm{CO}_{2}$.

Traditional physiological theory postulates that $\mathrm{HR}$ is determined mainly by a dynamic balance between sympathetic stimulation and vagal inhibition. ${ }^{19}$ Sympathetic withdrawal or vagal stimulation produce a decrease in mean HR, whereas sympathetic activation or a decrease in vagal tone generate the opposite effect. These changes in autonomic balance usually act synergistically, although the activity of the right "chronotropic" vagal trunk is believed to be a major determinant of HR. ${ }^{20}$

Physiological stress such as the inhalation of $\mathrm{CO}_{2}$ can be assumed to produce a sympathetic stimulation and a concomitant vagal inhibition leading to a rise in mean HR. ${ }^{21}$ However, if the $\mathrm{CO}_{2}$ sensing structures have a lower dynamic sensitivity, either because of a low efferent discharge "response slope" or a high sensitivity threshold to inhaled $\mathrm{CO}_{2}$, the likely consequence would be a low sympathetic stimula- 
tion. This might result in an absent or delayed arousal and lack of a concomitant rise in HR in response to the excess of $\mathrm{CO}_{2} \cdot{ }^{21}$ Whether the lack of sympathetic activation is a consequence of a central inhibitory effect of $\mathrm{CO}_{2}$ cannot be deduced from our study. However, it should be noted that brain areas that are considered to be relay stations for the integration of blood pressure and HR control mechanisms (such as the arcuate nucleus ${ }^{22}$ ) are located close to the chemosensory area at the ventral medullary surface. Our observation that a failure to increase $\mathrm{HR}$ during $\mathrm{CO}_{2}$ breathing is related to a lower ventilatory response illustrates the close relations between $\mathrm{CO}_{2}$ sensitivity and cardiac control mechanisms. Notably, patients with central congenital hypoventilation syndrome who lack $\mathrm{CO}_{2}$ drive have an abnormal $\mathrm{HR}$ variability. $^{23}$

In addition to these putative central mechanisms regulating the ventilatory and $\mathrm{HR}$ response to $\mathrm{CO}_{2}$, two peripheral mechanisms are also likely to modulate the characteristics of the response.

The epithelial lining of the upper airway and tracheobronchial tree contains liquid, $\mathrm{H}^{+}$, and $\mathrm{CO}_{2}$ sensitive receptors. ${ }^{24}$ Stimulation of any of these receptor pools induces a slowing of respiration, bradycardia, and a rise in blood pressure. This response is more accentuated in infants and neonates. ${ }^{25}$ Infants with apnoea appear to have a particularly strong response to laryngeal stimulation with liquid and severe bradycardia, sometimes progressing to cardiac arrest, has been described. ${ }^{26} \mathrm{~A}$ hyperactive chemoreflex resulting in a marked slowing of respiration and cardiac rhythm in response to stimulation of airway $\mathrm{CO}_{2}$ receptors could explain the concomitant decrease in HR and the trend towards higher post-challenge transcutaneous $\mathrm{CO}_{2}$ values in apnoeic infants. ${ }^{26}$

A finding not entirely explained by a hyperactive chemoreflex of the airway receptor is the time course of the altered $\mathrm{CO}_{2}$ response. Airway receptor stimulation is known to produce a relatively long lasting inhibition of breathing but a relatively short lasting vagally mediated bradycardia. ${ }^{27}$ The sustained decrease in $\mathrm{HR}$ during $\mathrm{CO}_{2}$ challenge appears different from this reflexly induced vagal bradycardia, ${ }^{21}$ and such reactive long lasting bradycardia has to our knowledge not been described previously. This type of response seems to be typical of apnoeic infants because siblings of infants who died of SIDS do not show this type of reaction. ${ }^{28}$

In summary, our study has shown that a significant proportion of apnoeic infants do not have the expected increase in HR during moderate $\mathrm{CO}_{2}$ challenge. We suggest that this is caused by a lack of sympathetic stimulation as a result of a hyperactive chemoreflex inhibition of respiration and $\mathrm{HR}$ rate or an altered $\mathrm{CO}_{2}$ sensitivity threshold.

The authors thank M Wennborg and S Öhman-Spetz for their skillful and devoted assistance. This study was supported by grants from Swedish SIDS Association and Swedish Medical Research Council B96-27X-11265-02B.

1 von Euler C, Lagercrantz H. Neurobiology of the control of breathing. New York: Raven Press, 1987.

2 Walker D. Peripheral and central chemoreceptors in the fetus and newborn. Annu Rev Physiol 1984;46:687-703.

3 Kemp JS, Kowalski RM, Burch PM, Graham MA, Thach BT. Unintentional suffocation by rebreathing: a death scene and physiologic investigation of a possible cause of sudden infant death. F Pediatr 1993;122:874-80.

4 Skadberg BT, Oterhals A, Finborud K, Markestad T. CO rebreathing: a possible contributory factor to some cases of sudden infant death? Acta Paediatr 1995;84:988-95.

5 Rigatto H, Brady JP, Torre Verduzco De La R. Chemoreceptor reflexes in preterm infants: II. The effect of gestational and postnatal age on the ventilatory response to inhaled and postnatal age on the ventilatory resp

6 Alvaro RE, Weintraub Z, Kwiatkowski K, Cates DB, Rigatto $\mathrm{H}$. A respiratory sensory reflex in response to $\mathrm{CO}_{2}$ inhibits breathing in preterm infants. F Appl Physiol 1992;73:155863.

7 Parks YA, Paton JY, Beardsmore CS, et al. Respiratory control in infants at increased risk for sudden infant death syndrome. Arch Dis Child 1989;64:791-7.

8 Prechtl HFR. The behavioural states of the newborn infants [review]. Brain Res 1974;76:185-212.

9 Harper RM, Schechtman VL, Kluge KA. Machine classification of infant sleep state using cardiorespiratory measures. Electroencephalogr Clin Neurophysiol 1987;67: 379-87.

10 Alvaro RE, De Almeida V, Kwiatkowski K, Cates D, Kryger $\mathrm{M}$, Rigatto $\mathrm{H}$. A developmental study of the dose-response curve of the respiratory sensory reflex. Am Rev Respir Dis 1993;148:1013-17.

11 Lagercrantz H, Broberger U, Milerad J, von Euler C. Ventilatory studies in two older infants with prolonged apnea. Acta Paediatr Scand 1980;69:545-8.

12 Hunt CE: Impaired arousal from sleep: relationship to sudden infant death syndrome. F Perinatol 1989;9:184-7.

13 Davi M, Sankaran K, MacCallum M, Cates D, Rigatto H. The effect of sleep state on chest distortion and on the ventilatory response to $\mathrm{CO}_{2}$ in neonate. Pediatr Res 1979;13: 982-6.

14 Adams JA, Zabaleta IA, Stroh D, Johnson P, Sackner MA. Tidal volume measurements in newborns using respiratory inductive plethysmography. Am Rev Respir Dis 1993;148: $585-8$.

15 Calder NA, Williams BA, Kumar P, Hanson MA. The respiratory response of healthy term infants to breath-bybreath alternations in inspired oxygen at two postnatal ages. Pediatr Res 1994;35:321-4.

16 Williams BA, Smyth J, Boon AW, Kumar P, Blanco CE. Development of respiratory chemoreflexes in response to alternations of fractional inspired oxygen in newborn infant. F Physiol 1991;442:81-90.

17 Hazinski TA, Severinghaus JW, Marin MS, Tooley WH. Estimation of ventilatory response to carbon dioxide in newborn infants using skin surface gas electrodes. Pediatrics 1984;105:389-93.

18 Schafer T, Schafer D, Schlafke ME. Breathing, transcutaneous blood gases, and $\mathrm{CO}_{2}$ response in SIDS siblings and control infants during sleep. F Appl Physiol 1993;74:88102.

19 Porges SW. Orienting in a defensive world: mammalian modifications of our evolutionary heritage. A polyvagal theory. Psychophysiology 1995;32:301-18.

20 Schwartz PJ, Salice P. Cardiac arrhythmias in infancy: prevalence, significance and need for treatment. Eur Heart f 1984;5:43-50.

21 Porges SW. Cardiac vagal tone: a physiological index of stress. Neurosci Biobehav Rev 1995;19:225-33.

22 Gozal D, Ohtake PJ, Rector DM, et al. Rostral ventral medullary surface activity during hypercapnic challenges in awake and anesthetized goats. Neurosci Lett 1995;192:8992.

23 Woo MS, Woo MA, Gozal D, Jansen MT, Keens TG, Harper RM. Heart rate variability in congenital central hypoventilation syndrome. Pediatr Res 1992;31:291-6.

24 Sant'Ambrogio G. Information arising from the tracheobronchial tree of mammals. Physiol Rev 1982;62:531-69.

25 Harding R, Johnson P, McClelland ME. Liquid-sensitive laryngeal receptors in the developing sheep, cat and laryngeal receptors in the developin
monkey. $f$ Physiol 1978;277:409-22.

26 Wennergren G, Hertzberg T, Milerad J, Bjure J, Lagercrantz $\mathrm{H}$. Hypoxia reinforces laryngeal reflex bradycardia in infants. Acta Paediatr Scand 1989;78:11-17.

27 Fisher JT, Mathew OP, Sant'Ambrogio FB, Sant'Ambrogio G. Reflex effects and receptor responses to upper airway pressure and flow stimuli in developing puppies. $7 \mathrm{Appl}$ Physiol 1985;58:258-64.

28 Glomb WB, Marcus CL, Keens TG, Davidson Ward SL. Hypercapnic and hypoxic ventilatory and cardiac responses in school-aged siblings of sudden infant death syndrome victims. F Pediatr 1992;121:391-7. 